\title{
FUNCIONALIDADE E USOS DE ÁREAS VERDES URBANAS SOB $O$ OLHAR DA EDUCAÇÃO AMBIENTAL
}

Regiane de Sá Alberto ${ }^{1}$

Resumo: A dinâmica atual das formações urbanas nos leva a encarar os espaços meramente como físicos e artificializados e não ambientes de possibilidades para habitar e conviver. A manutenção de espaços livres vegetados, sempre foi justificada pelo seu potencial em propiciar qualidade ambiental, por meio das funções sociais, ecológicas, estéticas e educativas. Esta breve discussão pretende colocar em perspectiva comparativa, sob a óptica da Educação Ambiental, a função educativa das áreas verdes urbanas e seus usos e apropriações. Considerando que o ambiente influencia nas ações humanas tanto quanto é influenciado por elas, a funcionalidade educativa destes espaços estaria em suas instalações e ordenação espacial ou na ocupação e apropriação destes espaços?

Palavras-chave: Áreas Verdes Urbanas, Espaços Públicos, Educação Ambiental, Espaço Educador.

${ }^{1}$ Universidade Federal de São Carlos. E-mail: regianealberto@gmail.com

Revbea, São Paulo, V. 12, № 2: 296-317, 2017. 


\section{Introdução}

O termo "meio ambiente" foi utilizado pela primeira vez pelo naturalista francês Geoffrey de Saint-Hilaire (1835) em sua obra Études progressives d'un naturaliste, e adotada por Augusto Conte em seu Curso de Filosofia Positiva (MILARÉ, 2001). O conceito de "meio ambiente" é amplamente difundido como objeto de estudo da área de Ciências Naturais, mais especificamente da Ecologia. Para o ecólogo Ricklefs (2003), a definição de ambiente é "o que circunda um organismo, incluindo as plantas e os animais, com os quais ele interage". No dicionário de ecologia Dictionary of Ecology and Environmental Science, escrito por Henry Art e colaboradores (1998), encontramos a seguinte definição: "conjunto de condições que envolvem e sustentam os seres vivos na biosfera, como um todo ou em parte desta, abrangendo elementos do clima, do solo, da água e de organismo".

Entretanto existem outras muitas definições, nas mais diversas áreas do conhecimento. Para as áreas de Ciências Humanas, a exemplo citamos a psicologia, o ambiente é definido como sendo o "espaço vital do indivíduo", a totalidade dos estímulos que agem sobre o ser vivo, desde a gestação até a morte (ARNOLD; EYSENCK; MEILI, 1994). O ambiente seria "o conjunto de elementos que podem atuar sobre o indivíduo e que está constituído pelas coisas em meio a que vive, as pessoas com as quais está em contato e a atitude destas pessoas com respeito a ele" (PIÉRON, 1993). No âmbito da sociologia, "ambiente" é o conjunto de todos os fatores de natureza física do meio que afetam o indivíduo e tem seu papel representado pelas construções sociais da natureza (MCREYNOLDS, 1999) compreendendo, portanto, desde a paisagem até a mentalidade da época. A Lei brasileira 6.938/81, que dispões sobre a Política Nacional do Meio Ambiente, define o que se entende por meio ambiente como: "o conjunto de condições, leis, influências e interações de ordem física, química e biológica, que permite, abriga e rege a vida em todas as suas formas" (BRASIL, 1981).

No campo das Geociências, o "ambiente" é entendido como a junção de meio biológico, meio antrópico e meio físico. Encontra-se uma definição segundo Silva (2008) citando Press et al. (2006), para o qual ambiente seria o habitat humano, compreendendo uma delgada interface entre a Terra e o céu, onde forças interagem para moldara face do planeta. As forças tectônicas agem no interior da Terra somada as forças meteorológicas agindo dentro da atmosfera e hidrosfera mantendo um equilibrado ambiente na superfície terrestre onde a sociedade humana pode prosperar e crescer. Conforme a segunda edição da publicação do IBGE (2004) Vocabulário básico de Recursos Naturais e Meio Ambiente, "meio ambiente" trata-se do "conjunto dos agentes físicos, químicos, biológicos e dos fatores sociais susceptíveis de exercerem um efeito direto ou mesmo indireto, imediato ou em longo prazo, sobre todos os seres vivos, inclusive o homem".

Tendo em vista todas estas considerações sobre o que vem a ser "meio ambiente", vale salientar que esta categorização não está concluída e que uma definição ou ideia pode ser conectada com a outra. É arriscado afirmar um

revista brasileira educação ambiental 
'certo' ou 'errado', são apenas concepções sobre o mundo vivido, concepções estas que podem manter diálogos ou estabelecer interfaces, e uma pessoa pode utilizar uma definição ou outra, através da ação e da reflexão (SATO, 2002). Sobre essa questão, trabalhar na perspectiva de uma Educação Ambiental limitada a uma ou outra destas concepções seria incompleta e corresponderia a uma visão reducionista da relação com o mundo. Por esta razão, o importante não é encontrar uma definição para o termo, mas explorar as suas diferentes possibilidades (SAUVĖ; ORELLANA, 2001).

Leff (2001) é um dos autores que propõe desconstruir o conceito de ambiente como sendo uma categoria biológica e sugere construir uma nova significação em que o ambiente também seja uma categoria sociológica, configurada por valores, atitudes e saberes. Assim sendo, para seguir com esta discussão, o conceito de ambiente a se ter em vista não será um ou outro, numa perspectiva excludente ou antagônica. Considerando ser mais rico do ponto de vista educativo, para este estudo que se propõe sob o olhar da Educação Ambiental se faz pertinente traduzir ambiente numa combinação de todas estas concepções já citadas. Buscando compreender este ambiente como espaço da ação dos seres humanos, seja este espaço constituído de componentes físico, químicos e biológicos naturais ou destes mesmos componentes construídos, transformados, projetados pelas ações dos seres humanos. Com isto pode-se legitimar uma discussão a respeito do ambiente urbano.

$\mathrm{Na}$ visão dos sistemas ecológicos, segundo Odum e outros autores (1987), as grandes cidades ou sistemas urbanos ou áreas metropolitanas também podem ser trabalhadas como ecossistemas. Considerando-se os componentes básicos que compõem um ecossistema: fluxo de energia, comunidades de seres vivos e ciclagem de materiais, as cidades enquanto ecossistemas diferem dos ecossistemas heterótrofos (não autossuficiente) naturais por exigir cada vez mais do campo ou área rural para conseguirem sua manutenção. Como apresentam um metabolismo mais intenso, exige um influxo maior de energia, grande entrada de materiais - para uso comercial e industrial - e uma saída maior de resíduos que em geral necessitam ser retirados intencionalmente do ambiente urbano, sob o risco de se acumularem. Partindo de um entendimento sistêmico, advindo do campo da Ecologia, podese interconectara paisagem urbana com o todo, porção periurbana e rural, os redutos de áreas vegetadas, os cursos d'água, áreas de proteção permanente como nascentes e leito dos rios, o que permite repensar que tipo de conexões quer-se manter e restabelecer, a fim de buscar um sistema de relações mais sustentáveis.

O ambiente urbano pode ser interpretado como lugar onde diversos elementos encontram-se em relações dinâmicas, que implicam em vários processos simultâneos transformadores dos espaços natural e construídos, em interação com as configurações sociais, políticas e psicológicas (CAVALCANTI, 2008). As cidades alojam mais da metade da população humana mundial, e tem sido objeto de diversos estudos inclusive este, porque entendida como 
uma reunião de aspectos físicos, históricos, biológicos e sociais nos possibilita (re)conhecer e refletir sobre o tipo de agrupamentos que estamos construindo e que tipo de relações com os outros seres, que ali habitam, estamos escolhendo. Neste ambiente, os espaços são de materialidade e imaterialidades, não só constituídos na concretude de sua configuração física, mas vivos em suas inter-relações seres humanos/natureza/seres não humanos - como em um ecossistema. Por isso Lynch (2006) afirma que os elementos móveis de uma cidade e, em especial as pessoas e suas atividades, são tão importantes quanto às partes estacionárias na configuração do que é dito ambiente urbano. A cidade é constituída principalmente de relações simbólicas, em que os sujeitos a vivenciam também como "paisagem" que faz parte de suas histórias de vida (MAFFESOLI, 1984). Sendo assim, há que se considerar as possibilidades do planejamento urbano e a intencionalidade da ordenação espacial como sendo fatores que influem sobre os seres, suas ações e relações. $\mathrm{E}$ destes elementos últimos - seres, ações e inter-relações - como incidentes nesta intencionalidade primeira.

\section{Cidade como ambiente para Educação Ambiental}

A partir dessa concepção holística, é possível vislumbrar a cidade como ambiente, de forma que prédios, ruas, praças e jardins passam a ser espaços dinâmicos de troca, convivência e aprendizado. Mumford (2004) agrega aspectos importantes a esta visão ao afirmar que a cidade é capaz de unir épocas, o passado, o presente e o por vir, preservando e transmitindo para o futuro ideias que são materializadas no espaço. Na área de arquitetura e urbanismo uma abordagem humanística, ao menos no espaço das pesquisas, vem ganhando projeção nas últimas décadas. Alguns fatores tidos como condicionantes da percepção dos seres humanos sobre os espaços urbanos, a citar crenças, valores pessoais, culturais e sociais, cosmo visões e educação passam a ser considerados (OKAMOTO, 2002, p.10) quando se abordam temáticas como planejamento, expansão e funcionalidade. Pensar a cidade para além da simples construção e dos controles estratégicos de ordenação espacial leva-nos a conceber o ambiente urbano como uma experiência de conhecimento e de relacionamento entre seres humanos e suas realidades imediatas, onde coletividade e lugar habitado se inserem conjuntamente. Para Tuan (1983) essa experiência "implica da capacidade de aprender a partir da própria vivência". E vivenciando a cidade diariamente as pessoas constroem envolvimentos e conhecimentos.

Sob esta perspectiva, pode-se defender a educação como passível de ocorrer nos espaços mais diversos, já que, como afirma Freire (2004), a educação é detentora de muitos espaços de aprendizagem em si, aprende-se em todos os lugares, aprende-se atitudes e valores nos encontros com pessoas e realidades diferentes. Durante esses processos de relação dinâmica neste grande ecossistema urbano, o educar-se transpõe os limites escolares. A legislação brasileira fornece um conceito de educação que engloba, além do processo de escolarização formal, os processos formativos que ocorrem em

revista brasileira educação ambiental 
outros espaços, estabelecendo através da Lei 9.394/96que: "A educação abrange os processos formativos que se desenvolvem na vida familiar, na convivência humana, no trabalho, nas instituições de ensino e pesquisa, nos movimentos sociais e organizações da sociedade civil e nas manifestações culturais" (BRASIL, 1996). Uma das dimensões da educação que tem o seu potencial de ação voltado para, e originado em realidades que vão além do contexto dito de educação formal escolar é a Educação Ambiental. Como disposto no inciso VI do parágrafo $1^{\circ}$ do Artigo 225 da Constituição Federal Brasileira de 1988, o poder público esta incumbido de: "promover a Educação Ambiental em todos os níveis de ensino e a conscientização publica para a preservação do meio ambiente". Como coloca Guimarães (2007) o processo educativo, seja ele adjetivado como ambiental ou não, passa por gerar reflexão sobre a origem dos problemas, que inegavelmente ultrapassam os limites das salas de aula. Logo, este dinâmico cenário do ambiente urbano, revela-se como fértil campo para o exercício da Educação Ambiental.

A Política Nacional de Educação Ambiental explicita as características dessa educação que deve também se fazer em caráter não-formal: "Entendese por Educação Ambiental não-formal as ações e práticas voltadas à sensibilização da coletividade sobre as questões ambientais e a sua organização e participação na defesa da qualidade do meio ambiente" (BRASIL, 1999). Neste ponto, por entender que existem muitas leituras, diversas ideologias $e$ inúmeros fundamentos teóricos e métodos de investigação no campo da Educação Ambiental, faz-se pertinente enunciar a partir de qual perspectiva vamos partir para um diálogo com todas essas outras vertentes (CARVALHO, 2004). A autora Oliveira (2007) defende uma Educação Ambiental que deve ocorrer em todos os espaços, dentro e fora das instituições de ensino, enunciando alguns elementos que marcam essa abordagem transformadora e emancipatória deste processo educativo que buscasse ter como base para os olhares investigativos aqui propostos:

\begin{abstract}
Estamos falando de uma Educação Ambiental que não seja conteudística, centrada na transmissão de informações sobre o meio ambiente; que não seja normativa, isto é, aquela que procura ditar regras de comportamentos a serem seguidos, sem rever os valores nem refletir sobre nossa ação no mundo. Assim, acreditamos numa Educação Ambiental que promova a reflexão na ação, entendida como práxis educativa, e que nos permita identificar problemas e conflitos relativos às nossas ações e à nossa própria presença no planeta, condicionada por nossa forma de pensar, nossos valores, nosso tempo histórico, nossa cultura etc. e que reflete igualmente nossas escolhas cotidianas como produtores e consumidores de bens e serviços (OLIVEIRA, 2007, p. 105).
\end{abstract}

Identificada a Educação Ambiental que traz significado para os propósitos deste estudo, vale introduzir um conceito relativamente recente, que surgiu para atender algumas das dimensões pertinentes a esta Educação Revbea, São Paulo, V. 12, № 2: 296-317, 2017. 
Ambiental que se pretende em todos os níveis e esferas da sociedade. Servindo, particularmente, para esta discussão a respeito de espaços públicos urbanos onde atividades educativas têm potencial de se concretizar. O termo espaço educador foi utilizado por Carlos Rodrigues Brandão no texto do material elaborado para o Programa Municípios Educadores Sustentáveis MES, do Ministério do Meio Ambiente. Kunieda (2010) aponta que "ao se referir a espaços educadores o autor o define como um lugar de educação que principia no aqui, relacionando o lugar onde moramos ao lugar onde vivemos, sucessivamente até abarcar o planeta como um todo". Mais especificamente o citado material define estes espaços educadores como:

(...) estruturas criadas nos municípios, nas quais ou a partir das quais acontecem ações ou projetos voltados para sustentabilidade que devem ter por objetivo não só a transformação da qualidade de vida do município, mas também a definição e implementação do seu papel educador (BRANDÃO, 2005, p.166)

Ao adjetivar um espaço como "educador", fica explicito que se trata "do que ou daquele que educa", atribuindo uma ação ou qualidade ordinariamente humana a um espaço (KUNIEDA, 2010). Neste sentido, a autora cita Matarezi (2005) como um dos educadores que trabalha o termo e busca defini-lo, afirmando ser no momento em que as pessoas se utilizam dos "espaços e estruturas" do cotidiano com uma intencionalidade educativa que estes adquirem a qualidade de "educadores". Sendo essa potencialidade educadora realizada quanto mais coletiva, participativa, significativa e transparente for o processo de vivência neste espaço. Sendo assim, os espaços urbanos mostram-se então potenciais espaços educadores uma vez que o espaço público é lugar de convívio e de contato com os signos da memória coletiva (AZEVEDO, 1997). Loboda e DeAngelis (2005) pontuam que o papel desempenhado pelos espaços verdes nas nossas cidades tem sido uma conseqüência das necessidades experimentadas de cada momento ao longo da história, ao mesmo tempo em que reflete gostos e costumes da sociedade. Além disso, Bargos e Matias (2001) defendem a manutenção de áreas verdes urbanas, justificada pela qualidade ambiental que propiciam à população amenizando as conseqüências negativas da urbanização. Interferindo diretamente na qualidade de vida dos seres por meio do cumprimento de suas funções sociais, ecológicas, estéticas e também educativas.

\section{Objetivo}

Esta breve discussão objetiva analisar comparativamente o uso e a funcionalidade educativa dos espaços urbanos, particularmente sob a óptica da Educação Ambiental, como já explicitado anteriormente. A proposta compreende olhar para alguns espaços livres vegetados a fim de propor uma discussão sobre trazerem ou não em seus projetos paisagísticos uma

revista brasileira educação ambiental 
intencionalidade educadora, seja esta explícita ou não, que venha a se materializar em potencialidades concretas de atividades de Educação Ambiental que possam justificar a denominação destas áreas verdes urbanas como espaços educadores. Destacando como objeto de análise aqueles projetos paisagísticos onde há evidências de estruturas educadoras, reveladas na identificação de alguma "intenção a propiciar-se aprendizagem aos nossos interlocutores" (MATAREZI, 2005), tendo em vista que se cumpram as funções propostas às áreas verdes urbanas.

Ao buscar reflexões e elaborações teóricas com relação aos usos e ocupação das áreas verdes urbanas em contraposição as funcionalidades a elas atribuídas, busca-se também desenvolver e compartilhar algumas reflexões sobre como e quando um determinado espaço pode vir a se torna educador ou estrutura pode vir a se tornar educadora.

\section{Metodologia}

Destacam-se como referenciais para o presente estudo os materiais resultantes de pesquisas que tem buscado superar a lacuna de definição consensual sobre os conceitos, usos e funções dos espaços urbanos. Salientando como relevantes aqueles que consideram, em específico, as funcionalidades e usos das áreas verdes urbanas ou espaços livres presentes nos ambientes urbanos. E destes, destacam-se ainda os materiais que classificaram e sistematizaram diferentes áreas verdes urbanas quanto a seu uso e função. Considerados, portanto, muito pertinentes como objetos de estudo desta breve discussão, servirá de material de analise as informações sobre alguns projetos paisagísticos de alguns espaços livres, mais especificamente praças, parques e calçadões do Brasil, disponíveis no site do grupo QUAPÁ2.

Segundo informações públicas divulgadas no ambiente virtual do QUAPÁ, trata-se este de um grupo de alunos de graduação/iniciação científica, mestrado e doutorado, que coordenados pelo Dr. Silvio Soares Macedo, centralizam suas atividades no Laboratório da Paisagem e recebem o apoio de pesquisadores associados em diversas partes do Brasil. O nome QUAPÁ tem sua origem nas iniciais do projeto de pesquisa em paisagismo, iniciado em 1994 na FAU - Faculdade de Arquitetura e Urbanismo da Universidade de São Paulo, que surgiu com o objetivo de estabelecer um panorama do "QUAdro do PAisagismo no Brasil" estudando os projetos de paisagismo no país em todas as suas escalas de abrangência.

Atualmente, segundo informações deste mesmo ambiente virtual, o projeto segue em andamento e objetiva a análise e sistematização do projeto paisagístico contemporâneo no Brasil, tanto na escala pública como privada, para entendimento das formas de projeto e configuração paisagística de

${ }^{2} \mathrm{O}$ ambiente virtual do Grupo QUAPÁ pode ser acessado em:

http://www.quapa.fau.usp.br/quapa desenv/default.htm

Revbea, São Paulo, V. 12, № 2: 296-317, 2017. 
espaços livres. Dos primeiros anos de trabalho, a dedicação prioritária do grupo alcançou dois objetivos que reverteram em um material disponível para consulta pública, destes: a criação de um painel geral sobre a evolução do Paisagismo Brasileiro e um Banco de dados sobre diversos projetos públicos praças, parques calçadões.

Os materiais categorizados no ambiente virtual do grupo de pesquisa QUAPÁ totalizam 1045 sínteses de informações, apresentadas como ficha técnica, de projetos paisagísticos de praças (844 projetos), parques (160 projetos), calçadões (41 projetos) e eventualmente outros espaços (como bosques, logradouros, unidades de conservação, piscinões, orquidários, horto e jardins botânicos) que foram foco de estudo do grupo. Para acessar estas sínteses gráficas, visuais e escritas são 15 opções de busca no banco de dados, que vão desde endereçamento da área, tipo do entorno, autoria e data do projeto, até configuração do espaço, condições de manutenção da área, existência de edificações, tipos de atividades, entre outras. Ao todo os materiais envolvem projetos paisagísticos estudados em 35 cidades dentre 22 estados do Brasil e no Distrito Federal. São categorizadas 25 possibilidades de atividades para todos os projetos paisagísticos indexados, sendo elas: Atividade esportiva, Atividade infantil, Atividade religiosa, Comércio, Conservação de recursos naturais, Construção abandonada, Contemplação, Educação Ambiental, Encontro de estudantes, Espera de ônibus, Estar, Eventos culturais/cursos, Eventos militares, Eventos musicais, Eventos políticos/cívicos, Eventos religiosos, Feira permanente, Feira temporária, Passagem de Carro, Passagem de pedestre, Passeios de barco, Passeios de pedalinhos, Pesca, Ponto de encontro, Recreação.

Para esta discussão, será projetado um olhar mais atento sobre as diferentes informações organizadas nesta plataforma aberta à consulta pública que figura o banco de dados sobre os projetos paisagísticos de espaços livres. Segundo informações do grupo, o banco de dados foi construído pelo estudo empírico dos pesquisadores do Projeto QUAPÁ que durante anos tem caminhado pelos subúrbios e áreas centrais das grandes cidades brasileiras, buscando detectar contextos, projetos paisagísticos, formas de apropriação e uso dos mais diferentes logradouros públicos e espaços livres. As informações então disponibilizadas são uma síntese gráfica, visual e escrita deste processo e permite ao usuário a leitura e cópia das informações de todas as praças, parques, calçadões e demais projetos até hoje estudados pelo grupo, mostrando para cada espaço a imagem o mais fiel possível do dia ou dias em que foi objeto de estudo. Esta plataforma virtual por trazer dados acerca de diferentes formas de apropriação e uso dos mais diferentes logradouros públicos e espaços livres, mostra-se especialmente interessante para esta discussão, quando a proposição é lançar um olhar sobre as relações que estabelecemos com o ambiente e as relações que se estabelecem entre as pessoas permeadas ou viabilizadas por estes ambientes.

A definição aqui adotada para área verde urbana será aquela de acordo com o Art. 8ํㅡ, parágrafo $1^{\circ}$, da Resolução CONAMA № 369/2006, a qual

revista brasileira educação ambiental 
considera área verde de domínio público "o espaço de domínio público que desempenhe função ecológica, paisagística e recreativa, propiciando a melhoria da qualidade estética, funcional e ambiental da cidade, sendo dotado de vegetação e espaços livres de impermeabilização". Como dito anteriormente, há uma série de estudos buscando resolver essa questão conceitual entre área verde, espaço livre e outros termos que são utilizados de maneira equivocada como sinônimos. Nucci (2001) realiza uma extensa discussão sobre o conceito em particular e a necessidade de que no planejamento urbano se incluam espaços livres, dizendo que as áreas verdes correspondem a uma categoria, "um subsistema do sistema de espaços livres", definidas como espaços verdes. E seriam estes os espaços que, segundo o autor, devem desempenhar estas funcionalidades ecológica, estética e de lazer. Steiner (2013) toma como referencial os estudos de Cavalheiro e Del Picchia (1992), e também Lima et al. (1994), para ressaltar que inicialmente as áreas verdes urbanas eram conceituadas preferencialmente como espaço livre, e com o passar do tempo foi dada ênfase ao termo área verde para designar aquelas que eram vegetadas. Outra definição bastante pertinente para área verde a ser também considerada nesta discussão é:

(...) as áreas verdes não são necessariamente voltadas para a recreação e o lazer, objetivos básicos dos espaços livres, porém devem ser dotadas de infraestrutura e equipamentos para oferecer opções de lazer e recreação às diferentes faixas etárias, a pequenas distâncias da moradia (que possam ser percorridas a pé) (MAZZEI et al., 2007, p. 39).

A autora ainda aponta que no ambiente urbano, estes espaços assumem várias funções, tais como:

(...) oferecer iluminação e ar aos edifícios altos situados no centro da cidade; dar oportunidade ao cidadão satisfazer suas necessidades de ocupação do tempo livre (física, psicológica e social) e propiciar que áreas relevantes, com características únicas, possam ser preservadas e conservadas. Assim, as principais funções dos espaços livres de construção são: recreativa, educativa, ecológica e estética ou paisagístico integradora (MAZZEI, et al., 2007, p.39).

Loboda e DeAngelis (2005 citando GUZZO, 1999, p.1-2) descrevem brevemente ao que se referem às principais contribuições destas áreas verdes, as funções ecológicas ocorrem na medida em que os elementos naturais que compõem esses espaços minimizam impactos decorrentes da industrialização; a função estética está pautada, principalmente, no papel de integração entre os espaços construídos e os destinados à circulação; a função social está diretamente relacionada à oferta de espaços para o convívio e o lazer da população. A destacar como relevante para este estudo em especial a Revbea, São Paulo, V. 12, № 2: 296-317, 2017. 
funcionalidade educativa, traduzida como: "possibilidade oferecida por tais espaços como ambiente para o desenvolvimento de atividades educativas, extraclasse e de programas de Educação Ambiental" (VIEIRA, 2004 apud BARGOS; MATIAS, 2011).

\section{Resultados e discussão}

Consideradas as funcionalidades oficialmente traduzidas para as áreas verdes urbanas a partir da literatura especializada na área. Tendo em vista o conceito de espaço educador para a dimensão educativa relativa à Educação Ambiental em espaços não formais. $E$ considerando a quantidade, qualidade $e$ disponibilidade das informações para consulta no banco de dados do ambiente virtual do Projeto Quapá. Procedeu-se uma busca, em uma espécie de recorte para pesquisa e análise, daqueles projetos paisagísticos que foram classificados/categorizados, dentro das possibilidades de atividades, para "Educação Ambiental".

Ao proceder-se com a pesquisa dentro das diversas atividades possíveis nas praças, parques e calçadões que tem seu projeto arquivado no banco de dados do QUAPÁ, uma vez selecionada a atividade "Educação Ambiental" como opção de busca, apenas dois (02) projetos retornam como resultado classificados para esta categoria de atividade. Seriam eles: o projeto paisagístico do Parque de Educação Ambiental Professor Mello Barreto da cidade do Rio de Janeiro - RJ e o projeto paisagístico da Praça Espanha da cidade de Curitiba - PR. A analise mais atenta dos materiais foi realizada para este parque e esta praça, já que são os únicos projetos categorizados para atividades de Educação Ambiental, voltando o olhar para as descrições sobre sua estrutura, formas, usos e equipamentos, disponibilizados em ficha técnica revertida como resultado da busca. Procurou-se identificar quais itens possivelmente traduziriam o cumprimento de sua funcionalidade estética, ecológica, social e educativa enquanto área verde.

Para o Parque de Educação Ambiental Professor Mello Barreto, grande parque linear as margens da Lagoa da Tijuca na cidade do Rio de Janeiro, a descrição do projeto paisagístico inclui em sua configuração bosque, gramado, vegetação, arvoredo esparso, chão batido e manchas de arbustos que se pode considerar como aqueles elementos correspondentes ao cumprimento das funcionalidades ecológica e estética desta área verde. A configuração deste parque também inclui rede de caminhos, o qual provavelmente permite a circulação de pedestres, além de incluir no projeto paisagístico elementos complementares como ciclovia e anfiteatro, que podem ser considerados itens que convidam ao uso e ocupação deste espaço urbano por parte da população. Estes seriam então elementos correspondentes ao cumprimento das funcionalidades sociais desta área verde. A descrição para este projeto paisagístico elenca como possibilidades de atividades contemplação e conservação de recursos naturais além da Educação Ambiental. 
Tabela 1: Ficha técnica referente ao projeto paisagístico do Parque de Educação Ambiental Professor Mello Barreto.

\begin{tabular}{|c|c|}
\hline \multicolumn{2}{|c|}{$\begin{array}{l}\text { Endereço: Av. José Silva de Azevedo Neto } \\
\text { Bairro: Barra da Tijuca } \\
\text { Cidade: Rio de Janeiro } \\
\text { Estado: Rio de Janeiro }\end{array}$} \\
\hline \multicolumn{2}{|c|}{$\begin{array}{l}\text { Data do Projeto: } 14 / 02 / 1995 \\
\text { Levantamento: } 27 / 03 / 2002\end{array}$} \\
\hline \multicolumn{2}{|c|}{ 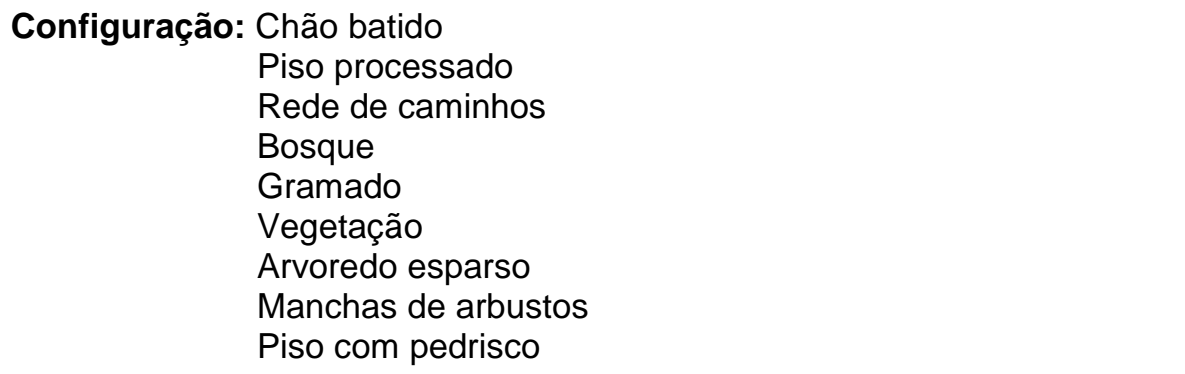 } \\
\hline Elementos Complementares: & $\begin{array}{l}\text { Ciclovia } \\
\text { Anfiteatro } \\
\text { Lixeiras }\end{array}$ \\
\hline \multicolumn{2}{|c|}{$\begin{array}{ll}\text { Atividades: } & \text { Contemplação } \\
& \text { Conservação de recursos naturais } \\
& \text { Educação Ambiental }\end{array}$} \\
\hline \multicolumn{2}{|c|}{ Tipo de Projeto: Parque } \\
\hline \multicolumn{2}{|c|}{ Fontes dos Dados: CAP - Fernando Chacel } \\
\hline \multicolumn{2}{|c|}{ Observações: ../txtquapa/Aat1Atr360co860.txt-> Impossível carregar } \\
\hline \multicolumn{2}{|c|}{ Manutenção: 1. Ótima } \\
\hline \multicolumn{2}{|c|}{$\begin{array}{ll}\text { Entorno: } & \text { Área mista } \\
& \text { Verticalizado }\end{array}$} \\
\hline \multicolumn{2}{|c|}{ Peculiaridades: ../txtquapa/Aat1Atr390co874.txt-> Impossível carregar } \\
\hline \multicolumn{2}{|c|}{ Código Quapá: RJ17 } \\
\hline \multicolumn{2}{|c|}{ Nome do Projeto: Parque de Educação Ambiental Professor Mello Barreto } \\
\hline 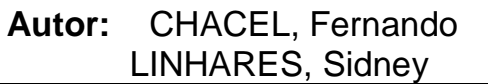 & \\
\hline
\end{tabular}

Para a Praça Espanha, extensa área na região metropolitana da cidade de Curitiba, a descrição do projeto paisagístico inclui em sua configuração gramado, arbustos de porte, cobertura arbórea, arvore de porte, além de elementos complementares como fonte, canteiros floridos e forrações que se pode considerar como aqueles fatores correspondentes ao cumprimento das funcionalidades ecológica e estética desta área verde. O projeto desta praça também inclui bancos, mirante, banca (comércio), centro cultural e biblioteca, elementos complementares e edificações que provavelmente permitem a circulação e convidam ao uso e ocupação deste espaço urbano. Estes seriam então elementos correspondentes ao cumprimento das funcionalidades sociais desta área verde. A descrição para este projeto paisagístico elenca como 
possibilidades de atividades contemplação e Educação Ambiental, além de destacar que todas as faixas etárias são usuárias do espaço.

Tabela 2: Ficha técnica referente ao projeto paisagístico da Praça Espanha.

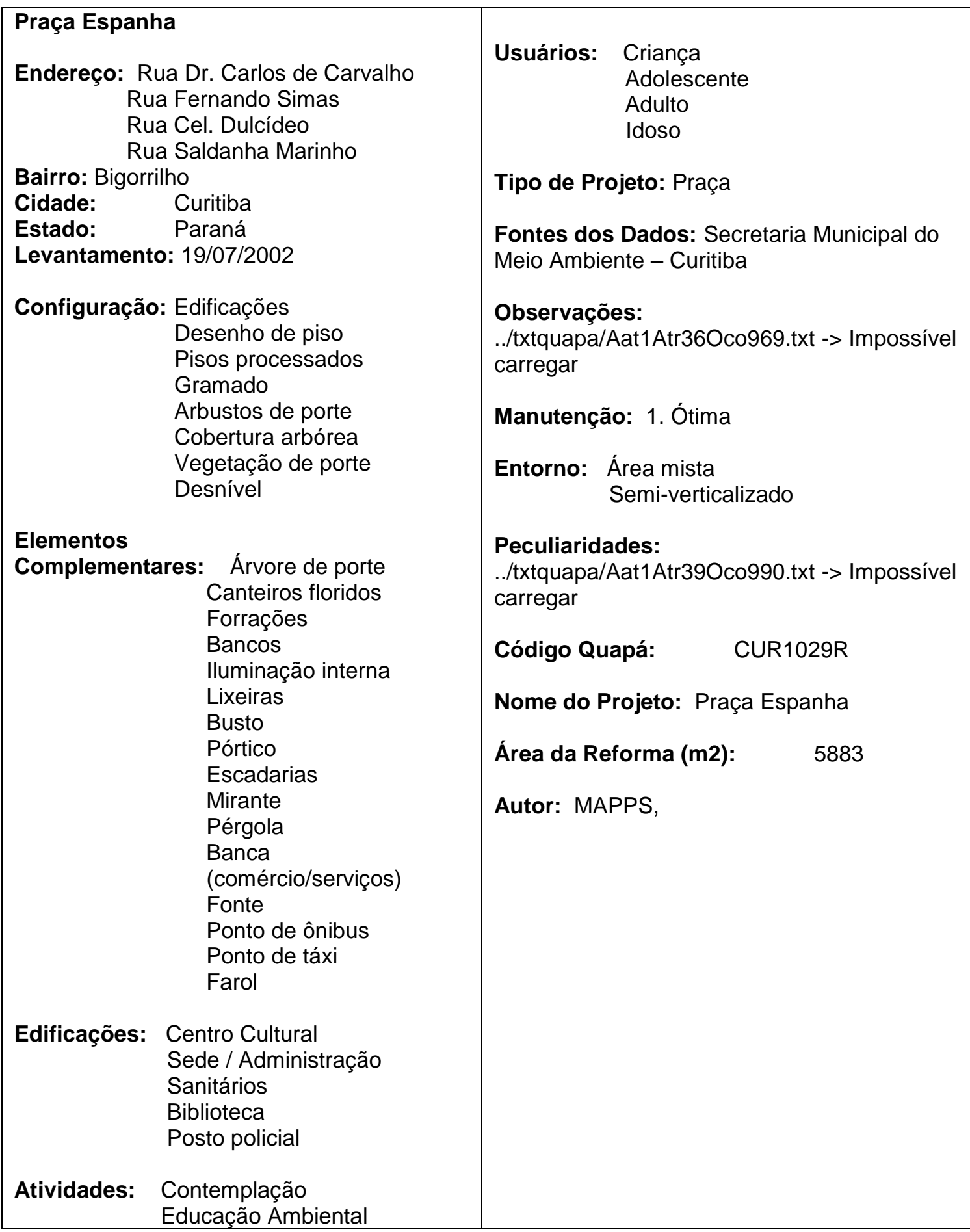


Tendo feita a apresentação das estruturas incluídas no projeto paisagístico destas duas áreas verdes e destacados aqueles elementos que corresponderiam ao cumprimento das funções estéticas, ecológicas e sociais destes espaços urbanos, seria interessante para a análise desta breve discussão, avaliar de maneira mais atenta aquelas estruturas que se pode indicar como correspondentes ao cumprimento da funcionalidade educativa destes espaços já classificados como potenciais à realização de atividades de Educação Ambiental. Ou seja, propõe-se identificar estruturas que uma vez impregnadas de intencionalidade educadora possam caracterizar o espaço de área verde urbana como um espaço educador. Para tanto, parte-se de uma argumentação pretensiosa de que o cumprimento de algumas funções urbanas apenas teria sentido com o efetivo uso e ocupação destes espaços urbanos e não tão somente com a garantia de instalação e manutenção de equipamentos públicos. Portanto deixa de tratar-se de um parâmetro em caráter funcional e passa a considerar-se um parâmetro de ordenação para uso e ocupação ${ }^{3}$.

Posto isso, toma-se como ponto de partida a presença de equipamentos urbanos como um primeiro item que qualificaria uma área verde ou um espaço livre ao cumprimento da função social no ambiente urbano. Entretanto de maneira alguma se pode afirmar serem estes os itens que garantem esta efetivação. Como apontam Henke-Oliveira et al. (1994) alguns espaços acabam com seu valor social bastante comprometido por apresentar baixa acessibilidade, "não basta ter a área à disposição da população, às vezes a área verde não apresenta condições de uso" seja por dificuldades devido o tráfego intenso no entorno, ou a curta extensão de área, ou baixo índice de arborização, ainda que esteja equipada e com a manutenção em dia, podem acabar como áreas não ocupadas. Logo, para este estudo em particular, considera-se que equipamentos urbanos públicos/comunitários na categoria de infraestrutura, circulação e transporte, cultura e religião, esporte e lazer, instalados em uma área verde acessível, adequadamente vegetada e manutenida, podem trazer uma mínima condição para promover o uso e ocupação destes espaços por parte da população. Assim, seguindo essa linha de raciocínio, se poderia supor que uma vez possibilitados o uso e ocupação diversificados e constantes, as possibilidades de atividades correspondentemente passíveis de ocorrer nestes lugares também poderiam aumentar. Dentre estas, atividades de Educação Ambiental estão inclusas. Portanto, com essas instalações pode-se levar a aumentar as possibilidades de cumprimento de algumas funções urbanas de tais espaços, porém, em nenhum momento se pode afirmar que garantem o cumprimento de tais funções por si só.

\footnotetext{
${ }^{3}$ Vale lembrar que o objetivo desta investigação não é propor um extenso e minucioso estudo a respeito do caráter funcional dos espaços em contraposição ao seu caráter de uso e ocupação, por entender que tal proposta versa no campo de revisões na área de arquitetura e urbanismo. Mas sim, pretende-se estabelecer uma contraposição, análise e discussão, sob a perspectiva de princípios e conceitos da educação ambiental, acerca de alguns aspectos referentes a função, uso e ocupação das áreas verdes urbanas.
}

Revbea, São Paulo, V. 12, No 2: 296-317, 2017. 
O mesmo não ocorre no caso das funcionalidades ecológicas e estéticas. Considerando o Parque de Educação Ambiental Professor Mello Barreto, resultado da busca no banco de dados do Quapá para projeto paisagístico com correspondência para atividade de Educação Ambiental, o mesmo projeto reverte também como resultado de uma busca por atividade de conservação de recursos naturais, o que nos remete diretamente a função ecológica. Tendo em vista a definição de Vieira (2004) citado por Bargos e Matias (2010) para a função ecológica como "provimento de melhorias no clima da cidade e na qualidade do ar, água e solo, resultando no bem-estar dos habitantes, devido à presença da vegetação, do solo não impermeabilizado e de uma fauna mais diversificada nessas áreas". Tal projeto paisagístico ao mesmo tempo reverte também como resultado de uma busca por atividade de contemplação, que remeteria a uma função estética, não exclusiva das áreas verdes, mas pertinentemente a elas associada. Consideração justificada pela definição de função estética dada como "diversificação da paisagem construída e embelezamento da cidade. Relacionada a este aspecto deve ser ressaltada a importância da vegetação" (VIEIRA, 2004 apud BARGOS; MATIAS, 2010). Apesar de corresponderem a uma legislação de parcelamento, uso e ocupação do solo as funções ecológicas e estética das áreas verdes não demonstram estar - pelo menos não para a perspectiva desta investigação - atreladas a presença, envolvimento, atuação da população nestes espaços para que suas funcionalidades possam ser consideradas efetivamente cumpridas.

Tomando como exemplo o parque e a praça resultados da busca por projetos para atividade de Educação Ambiental, para um olhar mais reducionista ou técnico materialista poder-se-ia indicar a presença de biblioteca, centro cultural e anfiteatro (ainda que sem uma descrição do tipo de uso do espaço ou atividade ali desenvolvida) como sendo os itens que justificam a categorização desta área verde como correspondente a atividade de Educação Ambiental. Estando, portanto, cumprida sua funcionalidade educativa enquanto área verde urbana. Entretanto estas instalações citadas não necessariamente garantem ou viabilizam atividades de Educação Ambiental. É fato que estas estruturas são idealizadas e instaladas a partir de uma intenção educativa, mas sem uso ou apropriação por parte da população não há como sua funcionalidade educativa se concretizar. Sem que haja nestas estruturas a (re)construção de uma nova ambientação provocativa dos corpos, emoções e mentes daqueles que fazem uso do espaço, no sentido de que se estimulem novas sensações e descobertas, não se pode afirmar que há possibilidades de inserção de uma Educação Ambiental efetiva.

A afirmação de que todo espaço educador é educativo, mas nem todo espaço educativo é educador, distingue um espaço educador de um educativo apontando uma especificidade dentro de uma generalidade. O primeiro é uma das modalidades do segundo, mas não o define unicamente (KUNIEDA, 2010). Algumas instituições como as escolas, e até museus e bibliotecas, são estruturas constituídas historicamente e reconhecidas como próprias da educação. Em quase todos os lugares, se fazem espaços padronizados, na sua forma e estrutura, pensados para regulação e não necessariamente

revista brasileira educação ambiental 
emancipação (MATAREZI, 2005). Construídas a fim de cumprir uma função e objetivos pedagógicos específicos que não são exclusivamente educadores, remetem a disciplina, organização, ordem, aspectos que não se pode afirmar assertivamente que sejam ou estejam atrelados a sua função educadora. Por isso o caráter educador pode estar associado ao espaço educativo, mas não limitado a ele.

Sob esta perspectiva aqui discutida, uma estrutura ou espaço terá potencialidade de se fazer educador na medida em que possibilita a todos e a qualquer um, acesso a problematização dos aspectos/termos/conceitos que figuram o desenho de seu processo educador, levando ao aprimoramento consciente e racional do interlocutor (MATAREZI, 2005) na medida em que concretiza seu aprender neste espaço. Assim sendo, não seriam somente as instituições biblioteca, centro cultural ou teatro, enquanto estruturas instaladas no espaço - seja do Parque Professor Mello Barreto no Rio de Janeiro ou no espaço da Praça Espanha em Curitiba, ou outros espaços urbanos espalhados pelas cidades brasileiras - que refletem a intencionalidade educadora destas áreas verdes urbanas e poderiam concretizar aí processos voltados a Educação Ambiental. $O$ autor ainda salienta a necessidade de que se esclareçam as características desta dimensão da aprendizagem que se possibilitaria suscitar nestes espaços e/ou com as mais diversas estruturas de intencionalidade educadora. Essa intencionalidade pode estar orientada a dois sentidos, pode ser aquela de que o outro venha a aprender na totalidade (ou quase) aquilo o que se propõe ensinar-lhe; ou pode ser no sentido de que o outro incremente a sua capacidade de aprendizagem a partir de sua trajetória de vida enquanto segue no caminho que estes aprendizados vão the propiciando escolher.

Posto isso, é possível afirmar que há outras estruturas que podem se constituir educadoras, em ambos os espaços revertidos como resultado do recorte da pesquisa aqui discutida. Tanto para a Praça quanto para o Parque pode-se buscar, em um estudo mais detalhado e cuidadoso, elencar outros aspectos que contribuem para a funcionalidade educativa destas áreas, por figurarem elementos que podem se impregnar de uma intencionalidade educadora. A título de exemplo, pode-se considerar a cobertura vegetal biodiversa como estrutura educadora. A própria configuração florística do projeto paisagístico de uma área verde, pode vir a ser estrutura educadora. Quanto maior for a diversidade e riqueza de espécies vegetais que constituem o espaço, mais em evidência estará sua qualidade e funcionalidade (enquanto ecossistema equilibrado e estável) frente a outras áreas com realidade de menor biodiversidade ou estrutura florística padronizada. Willison (2003), em um estudo de Educação Ambiental em jardins botânicos, evidencia a relevância de espaços vegetados para a promoção da educação voltada a conservação, salientando o papel de importância da flora na qualidade de vida humana: 
Os jardins botânicos desempenham um papel óbvio e vital na conservação vegetal, mas ela não pode ser bem-sucedida sem a ajuda da educação. Os jardins botânicos são criados exclusivamente com o objetivo de ensinar a importância das plantas para nossas vidas e o ecossistema global. Ao chamar a atenção para as ameaças que os vegetais e os habitats enfrentam, os jardins botânicos podem ajudar a sociedade a pensar em formas de proteção da biodiversidade (WILLISON, 2003).

Áreas de vegetação, em sua diversidade, podem ainda permitir que se evidenciem aspectos históricos de seu entorno e até da cidade como um todo. A composição florística pode suscitar apelo afetivo sobre o cuidado com as espécies ali presentes, seja para conservação enquanto se desenvolvem, ou pelos benefícios dos serviços prestados enquanto espécies frutíferas ou medicinais. Estes aspectos elencados a respeito da cobertura vegetal têm potencial intrínseco para levar ao desenvolvimento de identidade, alteridade, pertencimento, participação e controle social por parte da população para com os espaços de áreas verdes em questão. Princípios e conceitos que podem ser considerados imprescindíveis para que um processo de Educação Ambiental se efetive.

O esforço voltado para aplicação deste olhar educador mais atento à vivência, permite elencar outros tantos elementos complementares como estruturas educadoras, e assim caracterizar outras áreas verdes urbanas como espaços educadores, dentre tantos parques, praças, logradouros e calçadões que também estão descritos no banco de dados do Projeto Quapá. O que poderia resultar em nova proposta de categorização destas áreas incluindo-as como pertinentes para a opção de busca referente a atividade "Educação Ambiental". Seguindo com o exemplo utilizado anteriormente, considerando a cobertura vegetal biodiversa como estrutura educadora, outros 06 projetos paisagísticos, entre parques e bosques, categorizados para atividade "conservação de recursos naturais" poderiam ser também categorizados para atividade "Educação Ambiental", tendo em vista as possibilidades de se trabalhar aspectos de conservação da flora respaldados pelos processos educativos potenciais de ocorrer neste espaço.

No material elaborado para o programa Municípios Educadores Sustentáveis há uma descrição cuidadosa a respeito das estruturas que se propõem educadoras. Sendo que neste estudo considera-se que esta descrição pode também se estender para espaços que se propõem educadores:

Possibilitam a vivência cotidiana junto a estruturas que demonstrem ser alternativas viáveis frente ao modelo hegemônico. Além de exemplares as estruturas devem induzir ações e reflexões em prol da qualidade ambiental e de vida comuns. São capazes de reunir pessoas que desejam realizar ações conjuntas em prol da coletividade e, que ao mesmo tempo, querem rever valores, métodos 
e objetivos de ação, pois almejam a sustentabilidade e reconhecem a necessidade de se educarem nesta direção; aqueles que educam pelo simples fato de possibilitarem a demonstração de que alternativas ao modelo hegemônico são viáveis e podem propiciar a sustentabilidade socioambiental e a felicidade em seu sentido mais amplo (BRANDÃO, 2005).

Posto isso, pode-se elencar muitas outras áreas verdes categorizadas no Banco de Dados do Quapá capazes de somar em si aspectos que as classifiquem como espaços educadores segundo esta descrição. Mesmo que não estejam categorizadas para as atividades "Educação Ambiental", seriam espaços, pode-se dizer, capazes de "reunir pessoas que desejem realizar ações conjuntas em prol da coletividade e, que ao mesmo tempo, querem rever valores, métodos e objetivos de ação", a exemplo pode-se citar aqueles projetos paisagísticos revertidos como resultado para a busca de atividades "Ponto de Encontro", "Passagem de Pedestre", "Estar", por indicarem diretamente a presença de um coletivo onde se materializam encontros dos mais diversos. Outro exemplo seriam os projetos paisagísticos revertidos como resultado para a busca de atividades "Eventos Culturais/Cursos", que uma vez sob um olhar educador mais atento, se podem comportar estruturas para um evento ou curso, podem vir a figurar como espaços capazes de "induzir ações e reflexões em prol da qualidade ambiental e de vida comuns".

Entretanto, mais do que buscar elementos que possam re-categorizar as atividades que refletem a funcionalidade de praças, parques e calçadões agrupados no banco de dados do Quapá, as pretensões desta breve discussão, contrapondo funcionalidades e usos de algumas áreas verdes, estariam voltadas para ressaltar a importância de olhar estes espaços com mais apresso, critério e relevância. Por serem eles as possíveis - por vezes até únicas - alternativas para as atividades "Recreação" popular, são as garantidoras da sociabilidade, do bem viver e por consequência da qualidade de vida e saúde de massiva porção da população urbana. Corroboram esta defesa Loboda e DeAngelis (2005) quando pontuam a respeito dos únicos espaços de uso coletivo tenderem

a ser cada vez mais privados (shopping-centers, condomínios residenciais, edifícios polifuncionais) e não as praças, parques e vias. Tais espaços, assediados pelas condições pósmodernas, já não trazem consigo a significância de um tempo. O que leva a pensar que, talvez a população urbana envolta pela ideologia das novas tendências globalizantes, não esteja mais se identificando com um lugar em específico, seus aspectos sociais, culturais ou históricos.

Pode-se dizer que, em uma perspectiva mais radicalista, não fora os aspectos geoambientais do cumprimento das funções estética e ecológica, Revbea, São Paulo, V. 12, № 2: 296-317, 2017. 
quanto impermeabilidade, renovação atmosférica e descanso visual, as áreas verdes urbanas talvez nem estivessem mais inclusas nos planejamentos de ordenação espacial urbana.

Considerando os objetivos desta discussão, Matarezi (2005) expõe um princípio que pode ser a chave para viabilizar uma vivência significativa em um espaço potencialmente educador. E assim lançar uma luz sobre os aspectos que garantiriam a funcionalidade educativa de uma área verde urbana. O princípio seria de que tais espaços e estruturas não devem tratar de definir conceitos, mas contribuir para que eles possam ser percebidos de maneira sensível, experimentados concretamente e (re) significados com e a partir do interlocutor. Partindo desses apontamentos dois movimentos se fazem possíveis e coexistem, um que parte da pessoa e outro que parte dos espaços e estruturas com as quais convive. Portanto o interlocutor influencia neste espaço/estrutura e é influenciado também por ele. Entretanto, ambos estariam condicionados não só com o corpo, mas também com as estruturas e espaços que constituem a sociedade e o lugar onde se vive. Moser (1998) reitera esta ideia e afirma que somos diretamente influenciados pelo meio em que estamos, de forma que nossas atitudes mudam de acordo com o espaço físico. Sendo assim, a funcionalidade educativa de um espaço parece estar menos atrelada a suas instalações e equipamentos públicos e mais ao uso, ocupação e apropriação destes espaços e sua re-significação por parte da população.

Portanto, o que pode transformar um espaço vazio em um espaço cheio de significados e aprendizados é a qualidade e função das relações que são estabelecidas com este espaço e com suas estruturas. Seriam os objetivos pedagógicos que, intencionais ou não, se constituem nos múltiplos cotidianos que o ser humano vive no ambiente urbano. Seriam as mediações, vivências, (re)interpretações, representações, (re)significações, reflexões e ações que se constrói neste e a partir deste espaço, nestas e a partir destas estruturas e relações, que vem a configurar um espaço educador.

\section{Considerações finais}

Olhando para a realidade humana na modernidade, como habitantes de um meio construído e cada vez mais artificializado, fica evidente a precariedade de espaços vegetados que, enquanto espaços públicos, convidem a convivência, adequados para o lazer, para a recreação, para o descanso, para a coletividade na troca de saberes, quereres, emoções e afetividade. Espaços que permitam impregnar-se de significados e possam mediar/representar vias de aprendizagem das mais diversas para e com os seres que ali se inter-relacionam cotidianamente. Muitos destes espaços, quando existem, não correspondem as aspirações humanas de bem viver e conviver, ou são insuficientes frente à altíssima demanda da crescente população urbanizada.

Portanto mostra-se um campo bastante rico - além de urgente, tanto no que diz respeito a arquitetura e urbanismo quanto para a Educação Ambiental

revista brasileira educação ambiental 
e outras áreas - pensar as áreas verdes urbanas para além de seus benefícios físico ambientais como atenuante de ruídos, reoxigenadoras do ar, condicionadora de amenização climática e integradora da paisagem. Fatores que inegavelmente fazem-se importantes, porém limitam o planejamento e até a apropriação popular destes espaços que trazem intrínseco uma potencialidade educadora em amplo sentido.

O ideal seria a proposição de um plano de uso e ocupação pelos órgãos públicos responsáveis, em parceria com a comunidade do entorno das áreas verdes urbanas ou outros espaços em questão, para criação e manutenção de espaços livres configurados para atender as demandas locais. Possibilitando assim a maior gama de atividades a se desenvolverem nestes espaços que podem vir a se figurar educadores. Incluindo as atividades de Educação Ambiental como forma de suporte que pode favorecer o cumprimento das diversas funções que são indispensáveis e relevantes para o ambiente urbano onde a maior parte da população humana brasileira habita. Com vistas à funcionalidade educativa neste grande ambiente que é a cidade, constituído de múltiplos espaços, é importante ter em conta que, nas palavras de Matarezi (2005), mesmo "um espaço vazio pode estar cheio de ar, de esperanças, possibilidades, descobertas, aprendizados, vida".

\section{Referências}

ARNOLD, W., EYSENCK, H.J.; MEILI, R. Dicionário de psicologia. São Paulo: Loyola, 1994.

ART, H. Dicionário de ecologia e ciência ambiental. São Paulo: Melhoramentos, 1998.

AZEVEDO, M.T. A cidade contemporânea e seus desafios. Caderno de Arquitetura e Urbanismo, Belo Horizonte, n. 5, 1997.

BARGOS, D.C., MATIAS, L.F. Áreas verdes urbanas: um estudo de revisão e proposta conceitual. Sociedade Brasileira de Arborização Urbana. REVSBAU, Piracicaba - SP, v.6, n.3, p.172-188, 2011

BRANDÃO, C.R. Aqui é onde eu moro, aqui nós vivemos: escritos para conhecer, pensar e praticar o Município Educador Sustentável. Programa Nacional de Educação Ambiental. Brasília: MMA, 2005. 180p.

BRASIL. Ministério da Educação. Lei de Diretrizes e Bases da Educação Nacional. Brasília, 1996. 04p. Disponível em: $<$ http://www.planalto.gov.br/ccivil 03/LEIS/L9394.htm> Acesso em: 10 jun. 2015

BRASIL. Ministério do Meio Ambiente. Conselho Nacional do Meio Ambiente CONAMA. Resolução № 369/2006. Disponível em: $<$ http://www.mma.gov.br/port/conama/legiabre.cfm?codlegi=489>. Acesso em: 10 jun. 2015 
BRASIL. Ministério do Meio Ambiente. Política Nacional do Meio Ambiente. Brasília, 1981. OXX p. Disponível em: <http://www.planalto.gov.br/ccivil 03/leis/L6938.htm> Acesso em: 10 jun. 2015.

BRASIL. Ministério do Meio Ambiente. Secretaria de Articulação Institucional e Cidadania Ambiental. Departamento de Educação Ambiental. Política Nacional de Educação Ambiental. Brasília, 1999. 04p. Disponível em: $<$ http://www.planalto.gov.br/ccivil 03/Leis/L9795.htm> Acesso em: 26 mai. 2015

BRASIL. Presidência da República. Casa Civil. Subchefia para Assuntos Jurídicos.Constituição da República Federativa do Brasil de 1988. Brasília, 1988. 060 p. Disponível em: $<$ http://www.planalto.gov.br/ccivil 03/constituicao/constituicao.htm> Acesso em: 10 jun. 2015.

CARVALHO, I.C.M. Educação Ambiental crítica: nomes e endereçamentos da educação. In: LAYRARGUES, P.P. (Coord.). Identidades da Educação Ambiental brasileira. Brasília: MMA; Diretoria de Educação Ambiental, 2004. p. 13-24.

CAVALCANTI, C. Meio ambiente, desenvolvimento sustentável e políticas públicas. 3 ed. São Paulo: Cortez editora, 2001.

FREIRE, P.H. Pedagogia da Tolerância. Ana Maria Araújo Freire (Org.) São Paulo: Unesp. 2004

GUIMARÃES, M. Educação Ambiental: Participação para Além dos Muros da Escola. In: Vamos cuidar do Brasil: conceitos e práticas em Educação Ambiental na escola. MELLO, S. S., TRAJBER, R. (Coord.). - Brasília: Ministério da Educação, Coordenação Geral de Educação Ambiental: Ministério do Meio Ambiente, Departamento de Educação Ambiental: UNESCO, 2007.p. 85-93.

HENKE-OLIVEIRA, C.; CAVALHEIRO, E; SANTOS, J.E.; ALBRECHT, J.M.E; CASTILHO, H.J.; FOSCHINI. M.T.C.; SÁ, O.R.; SILVA, R.T; LIMA, R.N.; SILVA, R.L.; SANTOS, S.M. e BARBOSA, R.M. Caracterização preliminar das áreas verdes públicas em São Carlos - SP. In: Anais do II Congresso Nacional Sobre Arborização Urbana. São Luís, de 18 a 24 de setembro de 1994.

IBGE, Instituto Brasileiro de Geografia e Estatística. Vocabulário Básico de Recursos Naturais e Meio Ambiente. Ministério do Planejamento, Orçamento e Gestão. Diretoria de Geociências. Coordenação de Recursos Naturais e Estudos Ambientais. ed. 2. Rio de Janeiro. 2004

KUNIEDA, E. Espaços educadores no contexto do CESCAR (Coletivo Educador de São Carlos, Araraquara, Jaboticabal e Região/SP): do conceito à formação em Educação Ambiental. Tese (Doutorado) - Universidade Federal de São Carlos, 2010. - São Carlos: UFSCar. 145 f.

LEFF, E. Saber ambiental: sustentabilidade, racionalidade, complexidade, poder. Petrópolis: Vozes, 2001.

revista brasileira educação ambiental 
LOBODA, C.R., DEANGELIS, B.L.D. Áreas Verdes Públicas Urbanas: Conceitos, usos e funções. Ambiência - Revista do Centro de Ciências Agrárias e Ambientais. Guarapuava - PR. v. 1 no 1. 2005. p. 125-139.

LYNCH, K. A imagem da cidade. São Paulo: Martins Fontes, 2006.

MAFFESOLI, M. A conquista do Presente. Rio de Janeiro: Rocco, 1984.

MATAREZI, J. Estruturas e Espaços Educadores: Quando os espaços e estruturas se tornam educadores. In: FERRARO JÚNIOR, L.A. (Org.). Encontros e Caminhos: formação de educadoras/es ambientais e coletivos educadores. Brasília: MMA, Diretoria de Educação Ambiental, 2005. pp. $161-173$.

MAZZEI, K., COLESANTI, M.T.M., SANTOS, D.G. Áreas Verdes Urbanas, espaços livres para o lazer. Sociedade \& Natureza. Uberlândia - MG. ed. 01. v. 19. p. 33 - 43. Jun. 2007

MCREYNOLDS, S. A. Guia para o iniciante em sociologia do meio ambiente: definição, lista de jornais e bibliografia. Ambiente \& Sociedade, Campinas, n.5, p. 181-189, Dec. 1999.

MILARÉ, É. Direito do ambiente. 2 ed. São Paulo: Editora Revista dos Tribunais. 2001

MOSER, G. Psicologia ambiental. Estudos de Psicologia (Natal), Natal, v. 3, n. 1, p. 121-130, Jun. 1998.1 Disponível em:<http://www.scielo.br/scielo.php?script=sci arttext\&pid=S1413294X1998000100008\&lng=en\&nrm=iso >. Acesso em: 10 jun. 2015.

MUMFORD, L. A cidade na história: suas origens, transformações e perspectivas. São Paulo: Martins Fontes, 2004.

NUCCI, J.C. Qualidade Ambiental e Adensamento Urbano: um estudo de Ecologia e Planejamento da Paisagem aplicado ao distrito de Santa Cecília (MSP). ed. 2. Curitiba - PR: O Autor. 2008. 150 p. Disponível em: $<$ http://www.labs.ufpr.br/site/arquivos/qldade amb aden urbano.pdf>Acesso em: 10 jun. 2015

ODUM, E. P. 1988. Ecologia. Rio de Janeiro, Editora Guanabara Koogan S.A. $434 \mathrm{p}$.

OKAMOTO, J. Percepção ambiental e comportamento: visão holística da percepção ambiental na arquitetura e na comunicação. São Paulo: Ed. Mackenzie, 2002.

OLIVEIRA, H. T. Educação Ambiental - ser ou não ser uma disciplina: essa é a principal questão? In: Vamos cuidar do Brasil: conceitos e práticas em Educação Ambiental na escola. MELLO, S. S., TRAJBER, R. (Coord.). Brasília: Ministério da Educação, Coordenação Geral de Educação Ambiental: Ministério do Meio Ambiente, Departamento de Educação Ambiental: UNESCO, 2007. p. 103 - 111 
QUAPÁ. Quadro do Paisagismo no Brasil. Banco de Dados. Faculdade de Arquitetura e Urbanismo. Universidade de São Paulo. MACEDO, S. S. (Coord.). Disponível em: <http://www.quapa.fau.usp.br/quapa desenv/default.htm>. Acesso em: 07 jun. 2015.

RICKLEFS, R.E. A economia da natureza. 5 ed. Rio de Janeiro: Guanabara Koogan, 2003.

SATO, M. Educação Ambiental. São Carlos: RIMA, 2002.

SAUVÉ, L.; ORELLANA, I. A Formação Continuada de Professores em Educação Ambiental: a proposta EDAMAZ. In: SANTOS, J.E.; SATO, M. A Contribuição da Educação Ambiental à Esperança de Pandora. São Carlos: RIMA, 2001, p. 276.

SILVA, C. R. et al. Geodiversidade do Brasil: conhecer o passado, para entender o presente e prever o futuro. Cassio Roberto da Silva (editor). Rio de Janeiro: CPRM, 2008.264 p.

STEINER, C. Proposta de um Sistema Nacional de áreas Verdes. In: Anais do XVIII Congresso Brasileiro de Arborização Urbana. Nov. 2014. Anais... Rio de Janeiro - RJ. 12 p. Disponível em: <http://www.cbau2014.com.br/trabalhos/21103.pdf>. Acesso em: 15. Jun. 2015

TUAN, Yi-Fu. Espaço e lugar: a perspectiva da experiência. São Paulo: DIFEL, 1983.

WILLISON, J. Educação Ambiental em Jardins Botânicos: Diretrizes para Desenvolvimento de Estratégias Individuais. WILLISON, J (Ed). GREENE, J (Coord.). Rio de Janeiro: Rede Brasileira de Jardins Botânicos, 2003. 